\title{
EL HUMOR DE CASTELAO \\ (Visto por un escritor vasco)
}

\author{
KOLDO IZAGIRRE
}

No cabe duda de que hace falta ser muy sabio o muy osado para venir a hablar de Castelao a Galicia, y no digamos nada a Pontevedra, ciudad donde vivió y trabajó el gran artista. No me adornan ninguna de esas dos virtudes, y por eso ustedes se preguntarán qué es lo que puedo decir yo sobre el humor de Castelao, tema bien tratado ya por gran cantidad de especialistas; en particular, y de modo bien brillante, por Siro López, dibujante gallego al que también aplicaría el epíteto de genial. Por otro lado, debo de confesar que poco puedo aportar sobre el estudio del humor en una cultura que ha dado obra tan importante como $O$ Segredo do Humor, de Celestino Fernández de la Vega. Pero siempre se puede venir a Galicia a hablar de Castelao si uno es lo suficientemente ignorante, y ése es mi caso. No soy especialista en ninguna de las disciplinas que Castelao cultivó, no soy estudioso de la historia para hablar de su trayectoria política, soy un simple escritor, es decir, alguien que se permite hablar de todo sin tener mucha idea de lo que trata, pero que siempre procura caer ingenioso. Ya esto -si es que no les predispone al aplauso- me disculpa ante ustedes de antemano; pero tengo otra importante razón para hablarles del humor de Castelao: soy vasco.

¿Qué tendrá de especial el humor de Castelao para un vasco? Para mí, y cuando digo para mí recuerden ustedes que soy escritor, o sea, algo así como la conciencia pública de mi grupo -disculpen lo trascendentaloide-, Castelao es la personificación del artista que los vascos no tuvimos. Por ser Castelao universal, tengo derecho a apropiarme, como si fuese un oportunista hijo político Fraga, de su figura y de su obra. Por ser yo vasco tengo la obligación, a través de Castelao, de hacer un repaso del arte que desgraciadamente produjeron en su época los artistas de mi país. Y también del que no produjeron. Desgraciadamente, por supuesto. No perdamos el humor. 


\section{HUMOR VASCO}

Quizá algunos de ustedes recuerden la famosa sección Tiemble después de haber reído de La Codorniz, firmada por Rafael Castelman, nombre que, a pesar de sonar a seudónimo, lo es. Su dueño, Rafael Castellano, era un niño madrileño que veraneaba en Deba desde los cuatro años. Fue creciendo sano y robusto gracias, seguramente, al yodo cantábrico, y en ese período tan complicado de la pubertad se dio cuenta de que veraneaba en un sitio llamado País Vasco. Se afincó definitivamente en nuestra costa, y hoy es un escritor bilingüe. Uno de sus libros lo tituló "Cosas» de Euskalerria, inspirándose quizá en el género que Castelao creó. Porque Rafael Castellano es, además, uno de los pocos vascos que ha reflexionado sobre el humor, $y$ el humor vasco en particular.

La capacidad de comunicación es innata y universal, pero no así el código. El código sólo puede ser usado por quien lo conoce, los códigos suelen ser particulares. El humor es también una forma de comunicación, pero que tiene un código sociocultural, y a partir de cada código, afirma Castellano, hay un tipo de humor diferente. Lo que hace reír a un chino o a un italiano es diferente, lo que hace reír a un rianxeiro del siglo XV o a uno del XX, también es diferente; y es diferente también lo que hace reír a un doker de Vigo, a un señorito coruñés o a un labriego da terra chá. Y Rafael Castellano aporta un pedagógico símil basándose en la gastronomía: todos somos capaces de degustar con placer una merluza a la koxkera o una caldeirada de merluza, pero no cabe duda de que, aun siendo la base un mismo producto, son platos diferentes y perfectamente diferenciables. Existe, por lo tanto, un humor gallego, como existe un humor vasco. Claro que esto habría que matizarlo, porque dentro del humor gallego, como decíamos, cada grupo tiene su código particular. Esto es evidente, creo yo, en la obra de Castelao. El humor de los señoritos en el café coruñés poco tiene que ver con el de aquel labriego que contemplando un cartel taurino (por cierto, que en el cartel puede leerse que la corrida es en Santiago), exclama: «Lástima de bois!»

A los vascos se nos ha solido comparar con los japoneses, porque nos hemos comportado de manera ecléctica, adaptando lo que más nos gusta de otras culturas, con la ventaja de que nosotros no hemos tenido que salir al mundo como ellos, ya que nuestro país ha sido tradicionalmente lugar de paso (y algo tendrá que ver en esto el Camino de Santiago). Nuestra personalidad, en ese sentido, es híbrida, y parece ser que también nuestro humor es producto del mestizaje. Entre las diferentes influencias, Castellano resalta una hasta tal punto que, según él, el humor vasco es un humor esencialmente celta. Castellano hace un paralelismo entre el espíritu tabernario del vasco y el del irlandés, en el que la bebida y la borrachera juegan un papel de primer orden. El irlandés se presenta a sí mismo como pobre, beodo y comilón: un antihéroe, quizá un Pedriño (el amigo de Rañolas en Os dous de Sempre). Olentzero, el 
personaje mítico vasco que representa el solsticio de invierno, nuestro Santa Klaus, es también un pobre carbonero, glotón y bebedor... El irlandés y el vasco son microcósmicos, no se preocupan del ancho mundo, sino de su tierra y de sus gentes (han conquistado poco, no tienen imperios). Parece ser que tanto en el humor de los irlandeses como en el de los vascos el alcohol juega un importante papel, y son bastante dados a burlarse de todo tipo de autoridades. Esto es muy defendible a nivel de literatura oral y popular, porque, a falta no ya de universidades, sino de escuelas donde no se persiguiera la lengua vasca, nuestra universidad ha sido la sidrería. Refugio de pícaros y hogar de borrachos, desde luego; cueva de misóginos, de acuerdo; pero también pequeño territorio liberado para la fiesta y la libertad de expresión. En las sidrerías se bebía, se comía, se chismorreaba, se tomaba el pelo... y se improvisaban versos, especialmente satíricos: contra los curas, contra los usureros, contra los escribanos. «Ese versolarismo de taberna, que hiede», dejó escrito Aitzol, uno de nuestros teóricos. Ojalá aquel hedor se desprendiese también de nuestras telas y de nuestros dibujos.

\section{LO QUE CASTELAO NO PUDO VER}

«Xaneiro mil novecentos ventiún. Día ventiseis. Cheguéi a París. $O$ vir de Madrid non puden fitar a paisaxe de Baskonia.»

Así empieza el famoso diario de Castelao. Se le hizo de noche, y el artista no pudo ver nuestro paisaje. El tren atravesó túneles bajo rocas y túneles bajo nubes. Algunas luces dispersas aquí y allá que aumentan la negrura de las montañas, durmientes lomos prehistóricos. Anónimas estaciones de tren, trasbordo en Hendaia, bostezos. Es muy probable que en aquel viaje Castelao ni siquiera oyese una palabra en euskara. Es una pena que este gran artista «no pudiese contemplar el paisaje vasco» (¡tan de paso es nuestro país!). Algunos vascos, escritores y artistas mayormente, sentimos como si nos faltara algo, como si nos hubiesen robado una obra importante de nuestra pinacoteca nacional (que no tenemos, evidentemente). Porque da la casualidad que, como trataré de mostrarles en esta charla, tampoco nuestros artistas pudieron ver «el paisaje vasco».

Tuve noticia, por medio de un amigo, de que existía en el mundo un cuadro titulado Paissagem Basca, obra del gran pintor portugués Amadeu de Sousa Cardoso. Fui hasta Amarante, hermosa población a orillas del Támega, para contemplar el cuadro (y el cuadro de mi viaje deben enmarcarlo ustedes en unas simples vacaciones). Buscaba en Amadeu de Sousa la obra vasca que Castelao no pudo hacer, pensando que las afinidades luso-galaicas necesariamente lograrían un lienzo que aliviara mis frustraciones. ¿Qué esperaba del Paissagem Basca? No lo sabía muy bien, era algo difuso, difícil de expresar, pero 
muy sentido. En todo caso esperaba algo nuevo, una tela que no fuese folklórica, el paisaje vasco visto por el ojo de un artista no contaminado por nuestro ruralismo, algo más osado que el impresionismo de Regoyos, algo que nos identificara en la modernidad, una síntesis de reivindicación y universalidad. Tenía grandes esperanzas, Amadeu de Sousa era un pintor vanguardista, vivía largas temporadas en París. Incluso imaginé que aprovechando la marcha del tren Amadeu pintó el cuadro en técnica cinemática: manchas blancuzcas sobre fondo verde, rojo ajado de helechos, fugaces líneas rectas en masas de color... (algo que sin duda alguna espantaría a Castelao). Llegué por tanto a Amarante, me dirigí directamente al museo de la fundación Gulbenkian, subí las escaleras como un autómata sin mirar a las más que probablemente robadas esculturas africanas que me saludaban, y en el segundo piso me encaré con la pared de la izquierda, tal y como me habían recomendado que debía hacer. Allí estaba mi Paissagem Basca, un rectángulo perfectamente delimitado por la diferencia de blancos que la luz artificial había producido sobre la pared encalada. Y la placa no mentía, Paissagem Basca, Amadeu de Sousa Cardoso. Pero el Paissagem Basca estaba tan vacío como el ojo derecho de Camoens. Según me explicaron en secretaría, el cuadro había sido enviado a la exposición de Europalia, en Bruselas. Me consolé con la perfección que siempre tiene la saudade: yo buscaba en Portugal (en Castelao) el paisaje que no encontraba en mi país, y Portugal (Castelao) me ofrecía su vacío, para que aprendiese que yo era a un mismo tiempo sujeto y objeto, que lo que yo buscaba estaba en mí mismo, como diría Teixeira de Pascoaes: «meu canto é lus do sol em mim filtrada...»

Debo de confesar que perdí el interés por el cuadro de Amadeu de Sousa, preferí guardar el chasco como reliquia lírica de un amor imposible (pasándome de saudoso a saudosista). Hoy tengo una idea aproximada del dichoso Paissagem a través de reproducciones en estampas y láminas: es, efectivamente, algo que horrorizaría al joven Castelao, una montaña de ocres y amarillos donde se distingue una casa blanca, todo ello en técnica cubista. No, Amadeu de Sousa no vio nuestro paisaje desde el tren, lo vio en sus veraneos en Biarritz y, cómo no, le pareció idílico. Supongo que, como Pierre Loti, Amadeu maldeciría la llegada de la estúpida civilización al País Vasco, reserva natural que había que guardar para patrimonio de artistas y antropólogos, o para retiro de parisinos hastiados de modernez. Estoy seguro de que a Castelao no le gustaba el cuadro de Amadeu (si es que lo conoció), y no sólo por su rechazo del cubismo. Yo creo que Castelao hubiese humanizado mi paisaje, le hubiese dado ese aliento telúrico que tan bien sabe transmitir en su reducida obra pictórica.

\section{CASTELAO Y EL DONOSTIARRISMO}

Tengo una buena razón argumental para pensar así, y es que Castelao, a pesar de que no pudo ver el paisaje vasco, conocía nuestras ciudades, y 
sabía apreciarlas en su justa medida. Sigamos al rianxeiro en su visita al Louvre:

"Ollando a escultura grega que está no Louvre, iqué sei cantos centos de obras! decátase un axiña que a escultura que ainda hoxe se fai é unha repetición, unha parodia da grega. Non se dou un paso. Sair das salas gregas do Louvre pra ir ó Museo do Luxemburgo para fitar a seición de escultura, é sair da Grecia dos tempos idos, a ... (puntos suspensivos de Castelao) ¡qué sei eu! ... (puntos supensivos de Castelao) ... a ... (puntos suspensivos de Castelao), a San Sebastián.»

San Sebastián, donostiarrismo: nuevos ricos, moderado despilfarro, pretendida modernidad, cosmopolitismo barato, fiestas para veraneantes, sano humor, canturriadas en sociedades gastronómicas... Es decir, añado yo, una ciudad que compite con A Coruña por ser la más bonita... (puntos suspensivos míos)... la más bonita de... (más puntos suspensivos)... de España. ¡Cómo me identifico con el juicio de Castelao! Saben ustedes, yo sufro diariamente ese espíritu provinciano, ramplón, de tasca y playa, paisaje de miniatura y áreas seudo-románticas... La antítesis de Grecia, desgraciadamente, ha conseguido imponerse, y se refleja en ese estilo tardoparisino que en los años setenta creíamos superado para siempre, y que poco a poco ha ido renaciendo y adueñándose también de un Bilbao que busca su identidad en supervigilados metros de cristal y acero que sólo cubren la margen derecha (la de los ricos), museos de titanio que exponen la historia de la motocicleta americana o la moda de Armani, puentes de diseño en los que diariamente se rompe una pierna cuando llueve. Más allá el palacio Euskalduna, el nuevo auditorio, donde hace bien pocos años estaban los astilleros del mismo nombre. En su inauguración, un jubilado del astillero fue el encargado de romper la botella de champaña sobre el edificio, botadura de un buque que nos llevará por el interesantísimo arte de la opera. Ese San Sebastián que desprecia Castelao se va imponiendo en todos aquellos lugares donde se desmanteló la industria, y el turismo es la nueva fuente de energía que necesita una burguesía en busca de grandiosos signos de identidad, sean estos manejados desde Nueva York o comprados hipotecando la política cultural de decenas de años. No perdamos el humor: ustedes saben tan bien como yo que el sano regionalismo, es decir, la autonomía borbónica, produce megalómanos.

\section{NUESTRO AMIGO CASTELAO}

Castelao tuvo luego, durante la República, muchos contactos con los vascos, estuvo varias veces en nuestro país, dio mítines... No sé si tuvo tiempo de contemplar nuestro paisaje, quizá se le hizo siempre de noche, o quizá los pro- 
pios vascos le impidieron contemplarlo. De todas formas, en su actualísimo Sempre en Galiza, obra «seria» plagada de ironía, encontramos esta estupenda muestra de humor:

«Os republicáns eran anticlericaes, $e$, por este sentimento negativo, consideraban aos vascos como nemigos da democracia, incapaces de sentiren a República, e, pol-o tanto, indiños do dereito á liberdade que reclamaban. ¡Quén lles había de decir que un católico vasco resultaria máis progresista que un laborista inglés! ...»

No hay exageración alguna en las palabras de Castelao, la democracia cristiana vasca puede vanagloriarse de tener el único partido político ultracatólico del mundo que luchó contra el fascismo arma en mano, mientras el Papa bendecía las bombas que caían sobre ellos y las democracias europeas hacían la vista gorda. Nos gustan las paradojas, no perdamos el humor.

El primer tercio del siglo XX se caracteriza, en el País Vasco sur, por un gran desarrollo industrial, acelerado por los grandes beneficios que produjo el tráfico de mercancías durante la primera guerra mundial (cuando un solo flete Bilbao-Cardiff suponía la amortización completa del buque). La demanda de hierro trae fabulosos beneficios a la oligarquía, dueña de minas y empresas de transformación. Bajo esta cúpula que tiene su sede en la banca, los altos hornos y las navieras, se producen dos hechos importantes: la expansión del socialismo en la clase proletaria y el afianzamiento del nacionalismo en la pequeña burguesía. Dos grandes tendencias marcan la prensa, la literatura y el arte de la época: por un lado, la búsqueda de la especificidad vasca; por otro, el reflejo de las luchas sociales y la miseria de la clase obrera. La plena identificación de ambos ideales no se daría hasta los años sesenta-setenta, con la asunción, por parte de los sectores más activos de la intelectualidad y de los movimientos populares, del ideario de una nueva organización cuyo nombre es el de una letra del alfaheto griego.

\section{NACIONALISMO Y PICASSO}

Hay gente que se escandaliza porque Castelao se atrevió a decir de Picasso que era «un intelixente», y que no sabía dibujar. Yo admiro la sinceridad de Castelao, porque la suya no era una opinión interesada, no era una boutade a la defensiva, como lo fue aquel juicio de Zuloaga para justificar su propio conservadurismo: «Picasso estaba extraordinariamente dotado para ser un gran pintor, hasta el momento en que se salió de la pintura para entrar en lo que se llama cubismo.» Zuloaga, vasco pintor de motivos españoles, tenía toda una historia detrás para apropiársela y superarla. No lo hizo así, 
toda su obra no es mas que un calculado guiño comercial velado de pretendida profundidad castellana. Gustos aparte, Castelao tenía la plena conciencia (me remito a su diario) de que una obra gallega profunda, dadas las condiciones de su país, no tenía mas remedio que ser una obra fundacional. ¿Puede fundarse un arte desde la vanguardia? ¿Qué pasado pictórico, qué academicismo debía superar Castelao para poder hacer vanguardia, pero vanguardia nacional? ¿Son conciliables, los términos «vanguardia»y «nacional»?

Permítanme contarles una anécdota que creo sitúa bien la dificultad que tenían los nacionalistas de la época para asimilar las vanguardias. No sólo de la época, la anécdota que voy a contarles tiene lugar casi veinte años más tarde que Castelao opinara sobre los nuevos movimientos artísticos.

Un buen día de 1938 recibe Picasso la visita de Julio Jauregi, delegado vasco en París.

- Me han dicho que ha hecho usted un cuadro...

-Aquí está, mírelo.

Jauregi contempla mudo aquel collage de cabezas de toro, caballos relinchando, manos rotas, pájaros imposibles...

-Se titula «Guernica.»

-A eso venía -responde serio Jauregi- llamándose Guemica, lo lógico sería que...

- Mire, señor Irujo, yo pensaba regalárselo a la República, pero si me lo pide Agirre en persona, es para ustedes.

El delegado no pierde el tiempo. Del estudio de Picasso se traslada directamente a la sede del partido, rue Singer. Entra en el despacho de Jose Antonio Agirre, el lehendakari en el exilio. Jauregi pretendía un golpe de publicidad, pero Agirre, en este caso, se dejó llevar por sus gustos estéticos más que por su instinto político pedírselo.

- Conozco ese cuadro. No me dice nada. Tengo mucho trabajo, no voy a

Supongo que Agirre quería ver una epopeya a lo Siqueiros o a lo Rivera, la exaltación de la etnia resistente o martirizada, algo en el estilo del último Aurelio Arteta, o, si prefieren, del Castelao de Galicia Mártir, Milicianos y Atila en Galicia. Agirre no podía sentirse representado por un cuadro que carecía de «vasquismo" o, puestos en plan Borges, un cuadro que carecía de «vaquismo», epíteto que está inmejorablemente explicado en El Congreso, cuento del volumen El libro de Arena: «Nunca Fermín Eguren me pudo ver. Ejercía diversas soberbias: la de ser oriental, la de ser criollo, la de atraer a todas las mujeres, la de haber elegido un traje costoso y, nunca sabré por qué, 
la de su estirpe vasca, gente que al margen de la historia no ha hecho otra cosa que ordeñar vacas.» Todas las ediciones que conozco de este cuento incluyen ese relativo en la última frase. Creo que lo que Borges quiso decir se entiende mejor desplazándolo hacia el final. Efectivamente, corrijo el estilo de Borges: «(estirpe vasca), gente al margen de la historia que no ha hecho otra cosa que ordeñar vacas.» Es cierto que ahora los «que» relativo y adversativo que-dan demasiado cerca, pero les permito (que) construyan la adversativa con «sino», por ejemplo.

\section{VASQUISMO O VAQUISMO}

Lizardi murió prematuramente, $y$ al igual que el tópico pide que el accidente sea «absurdo», añadiré que murió «de cruel enfermedad», en el 33, y que al igual que pregunta Mendez Ferrín sobre Amado Carballo, podríamos también nosotros preguntarnos qué hubiera escrito un Lizardi tras el trauma de la guerra (si es que hubiese salido con vida, claro: era militante cualificado del PNV, y fue secretario del partido en Guipúzcoa). Xabier Lizardi está en la base de la moderna poesía vasca. Para quien tenga afición a la genealogía informo que es muy interesante comparar Os piñeiros mortos de Amado Carballo con su Zuahitz etzana. Fue fundador de Euskaltzaleak, asociación parecida a las Irmandades de Fala, fue político malgré lui... y también tuvo un hijo muerto en la niñez. Para que el paralelismo con Castelao sea mayor, les diré que comenzó su vida artística como dibujante y acuarelista.

Lizardi no continuó su incipiente obra pictórica. Se lo reprocho, pero no demasiado, pues contribuyó poderosamente a la modernización de la prosa periodística y desarrolló una obra poética singular que, curiosamente, basa su fuerza expresiva en la economía sintáctico-verbal, como si fuese un caricaturista que procura expresarse con el menor número de líneas posible.

Díganme si no son aplicables al ruralismo de Castelao estas confesiones, tituladas Tristezas de un jocoso sentimental, escritas en el año 29 (y no me hagan responsable del estilo, pues no he traducido el texto, se trata de uno de los pocos artículos que Lizardi escribió en castellano):

«Ancha playa. Amplio mar en libertad pacífica. Un tenue acolchado gris-oro velando el horizonte. Permítaseme una exclamación para hacer boca: ¿Qué hermoso es convalecer aqui envuelto en cien recuerdos luminosos de infancia, lejos de la labor forzosa con quien jamás hizo pacto de amiga la afición...! Prosigamos. 
«(...) Un pueblo se acurruca al pie de la montaña pintoresca. Es -en mi visión retrospectiva- humilde, pequeño y deliciosamente quieto; figúraseme que en él todo el mundo es pobre y feliz. Ayunos de gran industria, tan pronto pescan como cultivan su huerto. Veo racimos de chiquilleria que corren y juegan ruidosamente. Al son del tamboril -sin duda es domingo- se hartan de saltar las muchachas, ajenas a otra gala y atavio que el de su fresca juventud. $Y$ ante los portales sentadas alrededor de una mesita baja hay grupos de mujeres, ancianas muchas, que juegan apaciblemente al mus, bien provistas de alubias. De los labios todos, femeninos o varoniles, de los frescos como de los ajados, brota abundante la bella música de la lengua de cuna y por el aire parece expandirse, impregnándolo todo, algún perfume muy jugoso y nuestro, de reineta arrugada que aromó las sábanas de hilo en el cofre familiar (...).

"Quizá perdurará la belleza natural de este rincón, por cuanto no podremos tan fácilmente agotar la fuente de su música, arrancar de cuajo sus montes, ni desecar su mar. Sus calles, esas sí, probablemente nosotros nos encargaremos de enlugubrecerlas y ahogarlas, cambiando las casas alegres de dos pisos por ruines rascacielos, pretenciosos como señoritas pueblerinas enmodadas con un lustro de retraso. Lo que más abruma es pensar que su alma pueda llegar a ser como esas momias repulsivas de heldades egipcias que cuatro mil años antes de Jesucristo enloquecieron a los hombres.»

Yo al menos veo muchas afinidades entre este sentimiento hacia la vida natural y sencilla de Lizardi -sentimiento un tanto crepuscular, de acuerdo, incluso vaquista, si se quiere - y el amor de Castelao por su tierra. Pero falta o sobra algo fundamental a la semblanza de Lizardi, cuando afirma que en el pueblo que él sueña o añora todo el mundo es pobre y feliz: se crea un entorno de gentes ingenuas y sencillas, una reserva natural y espiritual en la que sentirse melancólicamente feliz (los fines de semana, a ser posible), un remanso de paz desde el que maldecir el fárrago de nuestra moderna civilización, se evita el conflicto, se coloca al pueblo vasco fuera de la historia (¡estamos dando la razón a Borges!)... No era ese, creo yo, el ruralismo de Castelao. Su nostalgia es por un futuro, no hacia el pasado. Y se me ocurre que quizá no quiso ver nuestro paisaje por un exceso de respeto hacia los vascos que le hablaban de esta arcadia feliz. Porque de haberlo visto, Castelao hubiera captado el deshaucio en la tristeza de una mirada, Castelao hubiera dibujado la tripa satisfecha del cura, el hipócrita escándalo de las beatas, la lascivia senil del indiano, la codicia del secretario de ayuntamiento, el paternalismo del administrador del marqués, y cómo no, la sonrisa burlona del labriego hacia el dominguero que le hablaba de patria vasca en castellano... Eso es lo que desgraciadamente no produjo el artista vasco contemporáneo de Castelao. Y cuando hubo visión crítica, nos faltó humor. 


\section{JOSE ARRUE}

Alberto, José, Ricardo y Ramiro Arrúe: cuatro hermanos, cuatro grandes artistas plásticos vascos. José era el más marcadamente humorista. En 1912 se presentó a una beca de la Diputación de Vizcaya. No se la dieron. El fallo del tribunal calificador incluye esta advertencia:

"Y en cuanto a Pepe Arrue, este desengaño debe servirle de enmienda. Ha reducido su arte a presentarnos cuadritos de socarronería rural, que nos regocijaban ante los escaparates. Y asi no se consigue la inmortalidad, sino solamente una fama que, por mucho que alcance, no llega más allá de Miranda de Ebro».

Se trata, al parecer, de una crítica socialista bajo capa de oficialidad foral. Por lo tanto, no es de extrañar que tenga su réplica en el periódico oficial del PNV, Euzkadi, en 1913, firmada por un tal Irrintzi, y titulado Lo que yo veo en Arrue:

«Pero, por Dios!, no pretended desterrar el ingenio cómico, hoy tan raro como las orquideas. Tiene el aldeano su aspecto cómico, gracioso, como lo tenemos nosotros, como lo tiene todo el mundo. Y Arrue ha sabido arrancarlo, como Prometeo el rayo de sol, y lo expresa en esa línea, en esa actitud, en ese contraste regocijante».

José Arrue expuso en el año 1917 en Madrid, en el III Salón de Humoristas (1917), organizado por el conocido crítico José Francés. Creo que allí Castelao tuvo palabras de elogio para la obra del vasco. Sin embargo, iqué lejos está Castelao del «contraste regocijante» o del «ingenio cómico»...

En 1924 José Arrue acude a III Salón de Humoristas de Barcelona. El primer premio es para el conocido dibujante catalán Luis Bagaría, y se concede un premio extraordinario a Arrue. En la comida de homenaje que se organiza en Bilbao se recibe la adhesión de Joaquín de Zugazagoitia:

«Fue usted, mi buen amigo, quien me dio, por vez primera, una interpretación plástica, rebosante de humor, de la realidad rural que tantas veces había contemplado. A través de su lápiz cobró para mí significación espiritual el mundo jocundo de nuestra aldeanería... ¿Qué duda cabe, amigo Pepe, que es usted nuestro primer costumbrista! Pasados los años, ;cuántas veces le he recordado a usted por esos museos frente a los cuadros flamencos de género! Aquellas primeras emociones que usted supo despertar en mí cuando aún andaba con la retórica y la geometría debajo del brazo, me ayudaban a penetrar intimamente en el humor popular y familiar de los flamencos". 
Flamencos, Brueguel... ¡lo más querido y admirado por Castelao, comparado con «el mundo jocundo de nuestra aldeanería»! Se trata de una gran manipulación, desde luego, pero ¿qué es lo que le falta a Arrúe, qué es lo que tiene Castelao, y no Arrue? ¿Por qué Arrúe no pudo interpretar el alma vasca, si es que existe, o dicho de otro modo, elevar a un plano artístico el sentimiento colectivo del pueblo, de sus clases populares? Arrue gusta a los señoritos y a los intelectuales, y qué duda cabe, a los nacionalistas de la época: pinta rasgos marcadamente raciales, paisajes idílicos (pero sin poesía), cultiva el anecdotario, domina la línea y el color, compone grandes ballets donde, dicen los críticos, cada personaje ocupa un lugar pertinente... Es un costumbrista. No inquieta, no ironiza, no detecta.

José Arrue también cultivó la caricatura en prensa. Incluso publicó en la famosa sección Maestros de la Historieta, en el Sol, como Castelao.

Jose Arrue era un patriota. Se movilizó con el ejército vasco, y en su glorioso repliegue fue capturado en Santander por las tropas italianas del general Manzini. Estuvo preso en Santoña y más tarde en el colegio de los escolapios de Bilbao, transformado en cárcel. Su campaña militar no le impidió seguir colaborando en prensa. Pero aunque sus historietas cobren una motivación más política, su estilo es el mismo, no hay una transformación estilística como en Castelao, quizá era artista de un solo registro. Su humor, aun con fondo bélico, sigue siendo trivial.

La casa-estudio de José Arrue fue ocupada y desvalijada, desperdigándose su obra entre personas adictas al nuevo régimen. Aun hoy cantidad de sus originales -como tantas otras cosas, y no solo estampas- siguen en poder de las familias de aquellos ladrones, sin que por ello podamos decir que no sean demócratas. Ustedes me entienden perfectamente, porque da la casualidad de que los originales del álbum Nos también le fueron robados a su autor.

\section{LOS ZUBIAURRE}

No eran cuatro, sino dos: Valentín y Ramón. El primero de ellos fue pintor de fuerte influencia simbolista, trabajando sobre lo que en la época se consideraba arquetipo de la etnia vasca, ya en los personajes, ya en las situaciones.

Ramón Zubiaurre no tenía la tendencia al dramatismo de su hermano, su vocación es humorística, de un detallismo que plagiando a Lizardi diríamos es jocoso y ligeramente sentimental. Supongo que les gustará saber que pasó su luna de miel en un hermoso lugar llamado Cambados, y que allí tuvo ocasión de conocer a Don Eugenio Barros, artista de otra disciplina a quien dedicó un lienzo, el retrato titulado El gaitero de Cambados. Y un tercer artista, el gran poeta Ramón Cabanillas, celebró así el cuadro: 


\begin{abstract}
Ese gaitero celta dos ollos azuados, cando o sol alumaba o vello campanario, cando estaban desertas a praza e mais o adro y o mar era un espello y o vento repousado bicaba as pedras negras do silenzoso pazo, véiño, e trúxoo a este lenzo, con todo o seu encanto. Don Ramón de Zubiaurre, o mozo pintor vasco.
\end{abstract}

Uniendo la obra de los Arrue y los Zubiaurre se forma el fondo alegre y despreocupado de la aldea vasca, ese folklorismo rural, ese tipismo para forasteros, ese falso naturalismo que tanto gusta en el Musée Basque o en las boutiques basquisants de la côte basque, o en los azulejos de las tabernas que se pretenden «de sabor local». Llegaron a la aldea y plantaron su caballete. Y desde esa cátedra contemplaron al aldeano, al pescador. Castelao entraba en la taberna, bebía, pedía fuego, escuchaba, apuntaba, en una palabra: aprendía. Nuestros pintores nacionalistas no, entre otras cosas, porque su mirada era externa, necesariamente superficial: el euskara ha sido para ellos, históricamente, cuando no un atraso, un elemento meramente simbólico.

Creo que fue Ortega y Gasset quien definió a los hermanos Zubiaurre como la encarnación más noble de la raza vasca: «Son pintores» dijo, y quería decir: no escriben, «y además son mudos» dijo, y quería decir: no saben hablar. He aquí una muestra de humor no ya negro, sino cruel: Valentín y Ramón Zubiaurre eran disminuidos físicos; sordomudos, precisamente. Más tarde el gran filósofo español -observen que no digo gran filósofo a secas- elaboró un poco más su opinión sobre los vascos, llegando a este axioma definitivo: «Ser vasco es, sin más, una renuncia nativa a la expresión verbal.»

Gentes bienintencionadas han pretendido explicarnos lo que realmente quería decir Ortega, argumentando que se refería a la falta de aptitud del vasco para la expresión verbal en castellano (en eso se basan precisamente todos los caricaturistas vascos de la época). Esta benévola interpretación la contra-argumentó hace tiempo un estupendo poeta, pintor e impresor vasco, Antonio Valverde, Ayalde, llevando la frase a un absurdo: «Ser francés es, sin más, una renuncia nativa a la expresión verbal en castellano», que también podría formularse así: «Ser español es, sin más, una renuncia nativa a la expresión verbal en vasco». ¡Aquí sí que hay algo de la visión certera de Cástelao! Señoras y señoros fisólofos, Ortega sabía muy bien lo que se decía. Seguía el rastro de los Unamuno, de los Baroja... «el euskara es una lengua incapacitada para la cultura». Ortega veraneaba en Zumaia (porque de allí era Zuloaga, y tenía con quien practicar el expresionismo verbal), y llamaba a Guipúzcoa «la tierra del bai». Lo que dijo de nosotros jamás lo hubiese dicho de los catalanes, porque el catalán era ya entonces una lengua de fuerte cultura académica, estimada por su burguesía. Lo que realmente Ortega quería decir era lo siguiente: «Hablar vasco es, sin más, una renuncia nativa a la expresión verbal.» 
JON ZABALO, TXIKI

No sé si se han dado ustedes cuenta: ¡Castelao hace hablar a sus personajes en gallego! ¡Qué nostalgia me invade! ¡Y qué rabia! ¡Qué no hubiera hecho un Castelao escuchando las ironías y las sátiras de los versolaris, nuestros regueifeiros, en plazas y tabernas! Y ustedes se preguntarán, ¿es que no hubo siquiera un artista, un dibujante que tratase a los vascos en vasco? Sí que lo hubo, y les aseguro que era un dibujante estupendo, implicado, además, en todos los géneros: decorados, portadas de libros, viñetas, encabezamientos, tebeos, ilustraciones, carteles... En algunos de sus dibujos, su parecido con Castelao es más que notable. Como Castelao, hizo un estudio de la arquitectura popular vasca. Como Castelao, ideó una grafía original. Había nacido en Manchester, su familia era euskaldun, de San Sebastián. Lo tenía todo, porque hasta fumaba en pipa... O casi todo para que hoy yo no tuviera que estar aquí llorando porque los vascos no hayamos tenido un Castelao, teniendo tanto que decir. Jon Zabalo, conocido artísticamente por Txiki, es nuestro primer dibujante nacional, pero no es nuestro Castelao.

Su talento estuvo al servicio de fines excesivamente pedagógicos y propagandísticos, nada de lo mucho que escribió a pie de imagen sirve $-\mathrm{y}$ sospecho que no lo escribía él- para lograr esa difícil síntesis que logra Castelao en sus Cousas da Vida, en las estampas de Nós. El pie del dibujo que les presento dice, en euskara: «¿Qué, hay pesca? Nada de nada. Ya me parecía a mí... ese mar es la lluvia de anoche." ¿Qué lejos está este humor de aquel (cito de memoria, disculpen) «As sardiñas volverían se os gobernos o quixeran...»!

La visión del mundo de Zabalo, por otra parte, es estrictamente ortodoxa, es un dibujante de partido. Difícilmente hubiese firmado -no difícilmente, sino que era imposible que firmase- aquello de «E que tal os rapaces? Téñoche un tan listo que ten quince anos e xa non cré en Deus». Zabalo es un buen ejemplo de ilustrador, de un artista que renuncia a la reflexión personal y al intimismo.

\section{DIVAGANDO EN IMÁGENES}

Admito que estoy dándole muchas vueltas al idioma. Pero no pretendo reducir la imagen a una copia más o menos fidedigna de la realidad. Por supuesto que una imagen tiene el poder de decir algo distinto de lo que muestra. El ramo de olivo es algo más que un elemento vegetal. Los pinos de Castelao, creo yo, significan algo más que un puro elemento paisajístico. Recordemos aquella acuarela donde un niño parece que duerme abrazado al tronco ligeramente mecido por el viento; produce una gran sensación de paz y dulzura; me lo imagino huido de la escuela, porque me hace recordar al rapaz que habla con 
el perro («Hoxe o maestro pegoume moito, sabes?»), o aquel otro en que la madre arrastra a su hijo hacia la escuela («Non quero ir porque o escolante pégame e a escola cheira que fede»)... El pino de Castelao me recuerda siempre la naturaleza no agredida, «a terra farturenta» de que hablaba el Castelao político. Es por eso, creo, que $O$ probe Xan, aquella lámina de Nós, apoya su espalda y su muñón en un rugoso tronco, no me importa que quizá no sea pino, el cuadro me lleva a las mismas conclusiones: cuello, pecho y muñón izquierdo desnudos contra la piel del árbol, como si el tronco fuese un regazo, como si Xan surgiese del mismo, como si su muñón fuese una rama cortada. Esta sensación de unión telúrica viene reforzada por la cabeza rapada de Xan, parece un recién nacido, y se asemeja a su madre-árbol en las arrugas. No creo que esté haciendo una interpretación forzada. Los discursos de Castelao sobre la patria están llenos de referencias a castañeiros y carballos. Reconozco que quizá en estas sensaciones mías tenga también algo que ver la elegía caureliana de Uxío Novoneira.

Pero más allá de lo que representan del mundo, las imágenes pueden estar cargadas de una significación particular. Sin embargo, esto no significa que las imágenes sean un lenguaje. Hablar del «lenguaje de la imagen» es en el mejor de los casos una metáfora, en el peor revela un gran desconocimiento de lo que es el lenguaje humano. No está de más advertir que cada vez que un publicitario quiere precisar el significado de una imagen, echa mano de la lengua. La lengua es así el complemento ideal de la imagen, a la que presta su cuadro conceptual. Precisar el significado no quiere decir agredir la imagen ni hacer un clónico linguuístico. Esta precisión será más o menos pertinente, más o menos adecuada, más o menos brillante, pero siempre necesaria. Así, tanto imagen como palabra, con desiguales ambiciones, contribuyen a la construcción colectiva del sentido, que también se sostiene sobre la lengua. Las Cousas da Vida de Castelao son el ejemplo perfecto.

\section{A MEMORIA DUN OLLO DE VIDRIO}

Castelao dejó mucho escrito sobre el arte y su función. Es un estupendo autor para ser citado, porque se adivina que sus ideas son producto de la meditación y de la experiencia propia, aunque algunas veces adquieran aspecto de boutade, algo perfectamente comprensible en un humorista. Yo citaría, como otros muchos, aquello de que un hórreo por cuyas tablas se vislumbra el cielo dice más del hambre que un tratado de economía. Imaginemos esa frase en dibujo: al puro paisaje se le coloca un primer término humanizado, se supera el bucolismo; el elemento tradicional va más allá del mero testimonio local, pues implica un mensaje, superando el arte por el arte, abriendo un camino propio para revelar la realidad o para golpear las conciencias. Eso es muy importante en un artista tan escritor como Castelao. En cuanto caricaturista no podía gus- 
tar del adorno ni de la adjetivación, para eso estaba el amigo Otero Pedrayo. Por eso nos dejó una buena crítica de los concienciadores iluminados, de los políticos baratos y de los doctos aburrientes en su Cousas: «Era un barbeiro de sábado que amaba os libros que non entendía...» ¡Cuántos intelectuales «profundadores» tenemos que aguantar! Lo he llamado humorista, no bromista. Castelao era un ollo no de vidrio, sino con memoria.

Creo que fue Pío Baroja quien dijo que sabíamos mucho de astronomía pero que aún no sabíamos definir el humorismo. Aunque aislásemos y mostráramos el genoma de la risa, de la carcajada, de la ironía, de la sátira... no lograríamos dar con la esencia del humorismo. Por decir algo, yo diría que el humorismo es la expresión libre de la sensibilidad inteligente, o de la inteligencia sensible, si prefieren. Y como expresión libre crea mundos propios donde la alusión es un método para cambiar nuestro punto de vista e intentar nuevos contrastes, riéndonos de ciertas seriedades o despreciando no pocas risas. Decía el gran Pirandello que el humorismo es parecido a la sombra, va junto con nuestro cuerpo pero por su lado, se alarga, se acorta, se quiebra, se aleja, se acerca, es decir, se guía por el espíritu de contradicción. El humorismo es una práctica libre, y se ejerce desde la subjetividad.

¿Tendrá algo que ver el humorismo, como pretende el amigo Rafa Castellano, con la psicología de los pueblos? ¿Tendrá algo que ver el humor de Castelao con su galleguidad? ¿Es humorista por gallego, o gallego por humorista? No lo sé, parece que los humores nacionales se definen tradicionalmente desde fuera. El español no deja de repetir que al cruzarse con un gallego en una escalera, no sabe si sube o baja... Perdonen por recordárselo, tienen que estar ustedes realmente hartos. Pero sigan en la escalera, por favor: así podremos seguir sintiéndonos ilusoriamente seguros de nuestra ruta.

Castelao no es un simple humorista, su rica personalidad tiene más de un registro. Pero si le quitamos el humorismo, le despojamos de uno de sus aspectos más importantes. El humor aparece a lo largo de toda su obra, ya les he comentado que hasta Sempre en Galiza está lleno de detalles de humor. Yo diría precisamente que en sus principales obras nos habla de la muerte y del sentido del humor, en un fluir inagotable. Puesto que no acepta el arte por el arte, ni la risa por la risa, su humorismo no es una abstracción, ni una fórmula estética. Castelao fue un gran crítico de todo dandysmo. Su humor es siempre mensaje, Castelao es un gran inoportunista. Está muy lejos del chiste, porque el suyo es el humor de un pueblo que acumula siglos de sufrimiento. Bagaría se caricaturizó a sí mismo quitándose una careta sonriente para mostrar su tristeza, y caricaturizó a Castelao con un rostro sonriente mientras de su corazón cae una lágrima. Castelao era, digámoslo ya, un humorista con conciencia (nacional y de la otra). Estaba en contra del humorismo de la Corte, rompió con la tradición que quiere al gallego y al portugués y al vasco como bufones. El golpe, la caída, la patada, el resbalón, el chapuzón, el tortazo, el tartazo... nada de estas clowneries encontraremos en Castelao, porque huye del gag. Sus caricaturas no 
son las aventuras de un monigote. Mucho menos encontraremos burla ni mofa. ¡Qué lejos está también del humor intelectualizado, del juego brillante! Nada mejor que citar a uno de los maestros del humorismo español, Miguel Mihura, para sopesar la grandeza de Castelao:

"El humor es un capricho, un lujo, una pluma de perdiz que se pone uno en un sombrero; un modo de pasar el tiempo. El humor verdadero no se propone enseñar o corregir porque no es ésta su función. Lo único que pretende el humor es que, por un instante, nos salgamos de nosotros mismos, nos marchemos de puntillas a unos veinte metros y demos una vuelta a nuestro alrededor contemplándonos por un lado y por otro, por detrás y por delante, como ante los tres espejos de una sastrería y descubramos nuevos rasgos y perfiles que no nos conocíamos. El humor es verle la trampa a todo, darse cuenta de por dónde cojean las cosas; comprender que todo tiene un revés, que todas las cosas pueden ser de otra manera, sin que dejen de ser tal como son, porque esto es pecado y pedantería. El humorismo es lo más limpio de intenciones, el juego más inofensivo, lo mejor para pasar las tardes...»

O fracasado da emigración está desnudo, puro hueso, mostrando las vértebras de su columna. Más adelante, otro cuadro, un primer plano de otro fracasado, que podía ser el mismo, porque toda la obra de Castelao es una larga secuencia sometida al decoupage, y podríamos reconstruír la película a partir de esos fotogramas. Y el primer plano dice: «Eu non quería morrer alá, ¿sabe, miña nai?». Nacer para emigrar, morir para descansar. Esta misma sencillez -la difícil sencillez, la jodida sencillez, que decimos amargamente los escritoresproduce un gran efecto en los textos. Y Castelao llega a esto a través de un proceso de depuración, al igual que en la caricatura. Hay un ejemplo muy ilustrativo en una de las visitas del labriego pobre al cacique. Cuando la publicó en $E l$ Sol la leyenda decía así:

"Y aquella hijiña que tenías? Estará crecidita, eh?

$Y$ contesta el labriego:

"A miña filla morreu de gripe..."

$Y$ el cacique:

"¡Vamos hombre! ¡Ya tienes una boca menos!"

Luego, cuando la publicó en Nos, el pie de estampa decía:

"A túa filla xa será unha moza, eh?»

Nada más. No hay respuesta. Se borró el chiste. Y leyendo esa única frase descubrimos la mirada de miedo y odio del labriego, la sonrisa del cacique se nos hace más lasciva, sus uñas más afiladas, sus orejas demoníacas, y en el cuadro del fondo se nos aparece un hidalgo místico del Greco, cuyas suponemos 
delicadas manos contrastan también con las del labriego, que sospechamos estrujan su sombrero ante el ave de rapiña. La risa fácil de $E l$ Sol ha desaparecido, se ha despojado de trivialidad, se ha desechado el ingenio para que trabaje el humor: leyendo esa única frase adivinamos el pensamiento del cacique. El dibujante ya estaba formado en la primera versión -el dibujo es exactamente el mismo en El Sol y en Nos-, pero el artista ha ido madurando hasta hacerse también escritor. Había llegado ya a la jodida sencillez.

Por su técnica y por su actitud, yo diría que Castelao es un dibujante lírico, y su obra un tratado de ética humanista. El nos diría que humorismo y humanismo son la misma cosa: el cambio de dos letras. Disculpen por habérmelo puesto tan fácil, el humor de Castelao es humanismo con intención. Su ojo nunca fue de vidrio. Su ojo fue ojo y oreja y corazón, un órgano múltiple y armónico al servicio de un arte sin concesiones.

Se dice que Castelao llegó a una identificación integral, casi mística, con su tierra. Yo creo que esa comunión se percibe precisamente en su humor más que en el cuerpo doctrinal que nos dejó o en los discursos en que define la patria, porque como dice Siro, «Castelao non tencionaba facer rir, senón surrir, pensar e sentir. Procuraba a solidaridade do lector coas víctimas da inxustiza e para eso dirixíase á súa intelixencia e á súa conciencia.»

$Y$ añado, disculpen ustedes mi castrapo:

A obra de Castelao é a grande paisaxe do pobo galego; un novo Pórtico da Groria moito más interesante, verdadeiro e galego que ise cacheno de pedra, por moito que sexa bendito. Ou ziquáis por iso mesmo.

\section{BIBLIOGRAFÍA}

ARIZTimuño, Jose, Obras completas. Erein, 1987.

ARRUE, Ramiro, Les écrits (1915-1966). Galerie de la Nuit. Bayonne, 1996.

Baroja, Pío, La caverna del humorismo. Editorial Caro Raggio, 1986.

Castellano De la Puente, Rafael, Cosas anecdotario de Euskalerría. Caja de Ahorros Provincial de Guipúzcoa, 1977.

F. DE LA VEGA, Celestino, O segredo do humor. Galaxia, 1963.

ElORZA, Antonio, Luis Bagaría, el humor y la política. Anthropos, 1988.

IZAGIRRE, Koldo, Castelaoz. Zehar, 6 zenb. Irail-Urria, 1990.

LARRINAGA, Jose Antonio, Los cuatro Arrue, artistas vascos. Bilbao, 1990.

LOPEZ, Siro, Castelao humorista. Xunta de Galicia, 1996.

MochizUKI, Takeshi, Ramón de Zubiaurre, el pintor y el hombre. Publicaciones de la Diputación Foral del Señorío de Vizcaya. Bilbao, 1980.

SAN MARTIN, Juan, Euskal umorea. Egan, 1987.

Siro, Castelao e os nenos, Castelao, Suplemento especial de La Voz de Galicia. Domingo 9 de xaneiro de 2000. 
Siro, $O$ humor liberador. Castelao, Suplemento especial de La Voz de Galicia. Domingo 9 de xaneiro de 2000.

UnsaIn, José María, Antecedentes del comic en Euskadi (1894-1939). Ttarttalo, 1989.

VAlVERdE, Antonio, Ayalde. Ibar ixillean. Sociedad Guipuzcoana de Ediciones y Publicaciones, 1970.

Varios autores. Castelao 1886-1950. Ministerio de Cultura. Dirección General de Bellas Artes y Archivos. Madrid, 1986.

VARIOS AUTORES. El negociado de incobrables (la vanguardia del humor español en los años veinte). Edición preparada por Jose Luis R. de la Flor. Ediciones de la Torre, 1990. 